\title{
PROTECTION OF AGRICULTURAL LANDS FROM ANIMAL INTRUSION THROUGH A SMART ROUTE
}

\begin{abstract}
Ramesh Gurusamy
Assistant Professor, Department of ECE, Kalasalingam Academy of Research and Education,

Krishnankoil, Virudhunagar (Dt), (India).

E-mail: ramesh.auvlsi@gmail.com

ORCID: https://orcid.org/0000-0001-7179-132X

Pradeep Narayanan

Assistant Professor, Department of ECE, Amrita School of Engineering,

Chennai, (India).

E-mail: narenpradeep@gmail.com

ORCID: https://orcid.org/0000-0003-0871-4887
\end{abstract}

Gujjula Harika

U. G. Student, Department of ECE, Kalasalingam Academy of Research and Education,

Krishnankoil, Virudhunagar (Dt), (India).

E-mail: harikagujjula05089@gmail.com

ORCID: https://orcid.org/0000-0003-2105-422X

Kadapana Pavani

U. G. Student, Department of ECE, Kalasalingam Academy of Research and Education,

Krishnankoil, Virudhunagar (Dt), (India).

E-mail: kadapanapavani@gmail.com

ORCID: https://orcid.org/0000-0003-4129-2030

Mana Tanmayi

U. G. Student, Department of ECE, Kalasalingam Academy of Research and Education,

Krishnankoil, Virudhunagar (Dt), (India).

E-mail: m.tanmayi99@gmail.com

ORCID: https://orcid.org/0000-0001-8090-2132

Recepción: 28/11/2019 Aceptación: 26/01/2021 Publicación: 30/11/2021

\section{Citación sugerida:}

Gurusamy, R., Narayanan, P., Harika, G., Pavani, K., y Tanmayi, M. (2021). Protection of agricultural lands from animal intrusion through a smart route. 3C Tecnología. Glosas de innovación aplicadas a la pyme, Edición Especial, (noviembre, 2021), 431-441. https://doi.org/10.17993/3ctecno.2021. specialissue8.431-441 


\section{ABSTRACT}

The working motto is to identify the animal intrusion into the agricultural fields and finding an immediate solution before it affecting the crops. The objective is to move the detected animals away from the crops. It becomes possible by the methodology of merging Passive Infrared (PIR) Sensor and motion capturing through camera across the field. An inbuilt GSM (Global System for Mobile Communication) with Arduino unit is used to detect the signals from the sensor and send that information to the farmers and nearby persons through message (SMS). For the land protection, farmer number will be feed early into the Arduino controller through LabVIEW coding. An alarm system is also dedicatedly connected with controller unit to give the security alert to humans and to divert the animals in opposite directions, i.e., out of the farms. The proposed system will detect any small intrusion happens in the field especially through any animals and pass the information as soon as possible to the concern persons. It results and ensures complete safety of fields from the animals thus preventing the farmers from huge loss and damage. Thus, here we have provided a low cost and energy efficient complete solution for intruder detection.

\section{KEYWORDS}

Agricultural Land, GSM module, LabVIEW, PIR sensor, Arduino. 


\section{INTRODUCTION}

Farming is the science and craft of developing plants and animals. Consider how much sustenance you eat every day. Albeit industrialized agricultural business has been fruitful in delivering substantial amounts of sustenance, the eventual fate of nourishment generation is in risk because of issues in horticulture. One of the serious issues in agribusiness is the harm of agrarian grounds by creatures.

It isn't feasible for ranchers to ensure whole fields or remain on field 24 hours and gatekeeper it. So here we propose "Assurance of Agricultural Lands from Animal Intrusion through a Smart Route" framework. This is a microcontroller-based framework. This framework utilizes a PIR sensor to recognize wild creatures drawing nearer close to the field. In such a case the sensor flags the microcontroller to make a move. In the event that the creature is identified the ringer produces sound to make the creatures move far from the field just as sends SMS to the rancher by utilizing GSM, with the goal that he may think about the issue and go to the spot on the off chance that the creatures don't dismiss by the caution (Zahrani, Ragab, \& Ul Haque, 2011). Creatures are an extraordinary test for ranchers all through the world. Creatures, for example, deer, rabbits, elephants, monkeys, cows, goats, hounds and numerous others may make genuine harm crops. They can harm the plants by benefiting from plant parts or essentially by running over the field and trampling over the harvests. Along these lines, creatures may effectively purpose critical yield misfortunes and incite extra money related issues (Forno, Malnati, \& Portelli, 2005). This guarantees total security of harvests from creatures along these lines ensuring the rancher's misfortune. Another perspective to consider is that creature crop assurance requires an especially careful methodology. As such, while using his harvest creation, each rancher ought to know and mull over the way that creatures are living creatures and should be shielded from any potential torment.

\section{EXISTING METHOD}

Since the 1960s, the measure of sustenance delivered through this sort of farming has expanded, and as of now there is enough nourishment created to encourage each human on Earth. The study on assurance of farming area from creature interruption there are 
numerous approaches to shield the harvests from creatures. One of the techniques to shield the harvest from creatures in certain zones ranchers produce bean stew smoke and consume elephant excrement or different materials that seethe and make substantial smoke and creatures will flee from the field. Another strategy to ensure the yield we may utilize wafers through this procedure creatures may move far from the field. Noisy commotion to drive off nosy elephants, Monkeys, and different creatures. Through these procedures there is no damage for creatures just as people. Radiations created by the sensor impact a creature through the warmth is delivered as an impact of radiation and creatures can't live by the warmth so they will move far from the field.

Yields in homesteads ordinarily assaulted by creatures like wild oxen, pigs, dairy animals, monkeys, elephants and so forth, this prompts colossal misfortunes for the ranchers. It isn't workable for ranchers to blockade whole field or remain in 24 hours. Fruitful ranchers dependably look to decide the palatable dimension of yield assurance by utilizing the advances, for example, creature interruption discovery.

At last, we proposed a standout amongst the best strategies to shield the harvest from creatures. This framework distinguishes the creatures by utilizing the latent infrared sensor (PIR) and movement catching through camera over the field. It produces the caution to alarm the people and make the creatures move far from the field. The GSM (Global System for Mobile Communication) is additionally required which is utilized to create SMS the famers get the data about the creature went into the field. Rancher gets alert through this framework and may think about the issue and go to the spot which is creature gone into the field. It guarantees totally security of yields from creatures. 


\section{MATERIALS AND METHODS}

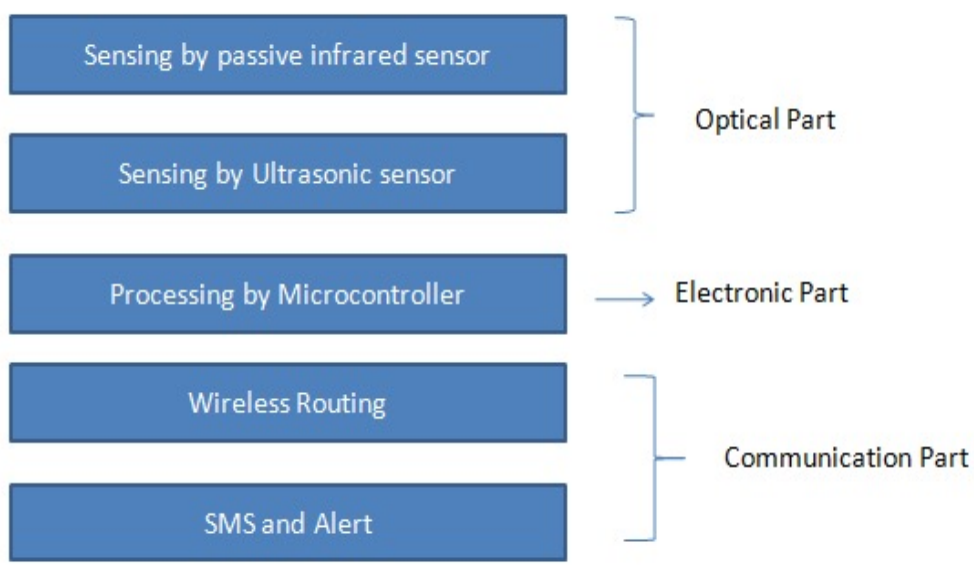

Figure 1. Parts of agriculture Intruder detection.

Source: own elaboration.

\subsection{DESCRIPTION OF OPTICAL PART}

It comprises of Passive Infrared sensor (PIR). At the point when an interloper goes into the field, the PIR sensor detects the gatecrasher. From that point, the detected information from PIR sensors is prepared by the miniaturized scale controller present in electronic part.

\subsection{DESCRIPTION OF ELECTRONIC PART}

After the recognition of an interloper, the picture is caught by utilizing a Camera.

\subsection{DESCRIPTION OF COMMUNICATION PART}

At last, in correspondence part, the GSM innovation is utilized to create SMS to the rancher's mobile phone, and at the same time, an alert is produced in the field with the goal that interloper may flee from the field and by getting the SMS, the rancher gets the data about the passage of a gatecrasher in the field.

While the creatures going into the field, the PIR sensor recognizes development on the grounds that the human or creature body emanates heat vitality in a type of infrared radiation. 


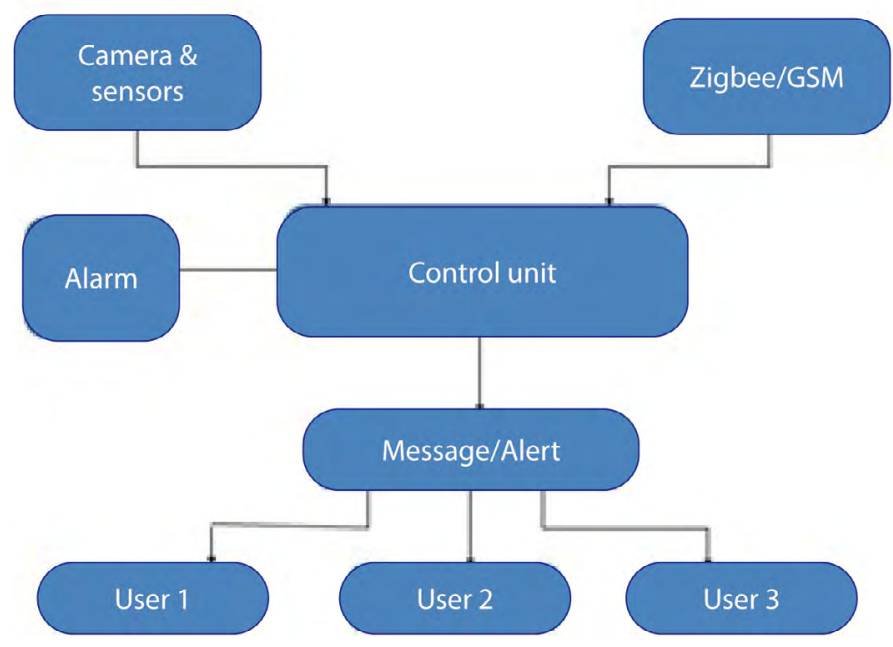

Figure 2. Block Diagram for animal intruder detection.

Source: own elaboration.

The module has only three sticks, a Ground and a VCC for controlling the module and a yield stick which gives high rationale level if an article is distinguished. Interfacing PIR with the microcontroller is simple and straightforward. The movement can be recognized by checking for a high flag on a solitary I/O stick. When the sensor heats up the yield will stay low until there is movement, at which time the yield will swing high for two or three seconds, at that point return low. Likewise, it has two potentiometers. One for changing the affectability of the sensor and the other for altering the time the yield flag remains high when the article is recognized. With the assistance of a camera, we can come to realize that, particularly which creature going into the field by picture preparing. By GPS module while the creatures going into the field, Due to this module, the sensor sends the data to the client (human particularly rancher). At that point, by the message from the sensor to the human can ensure the agriculture crops/fields from creatures. 


\section{RESULTS}

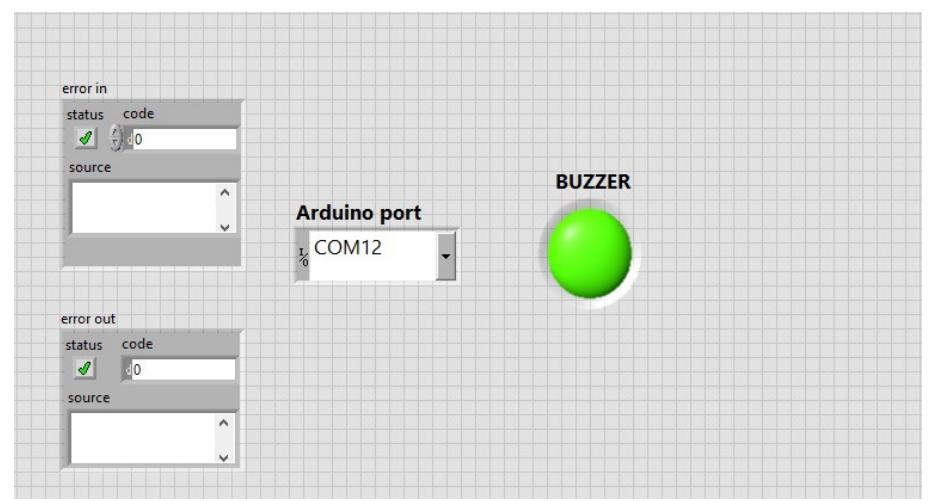

Figure 3. Front panel for PIR Sensor detection.

Source: own elaboration.

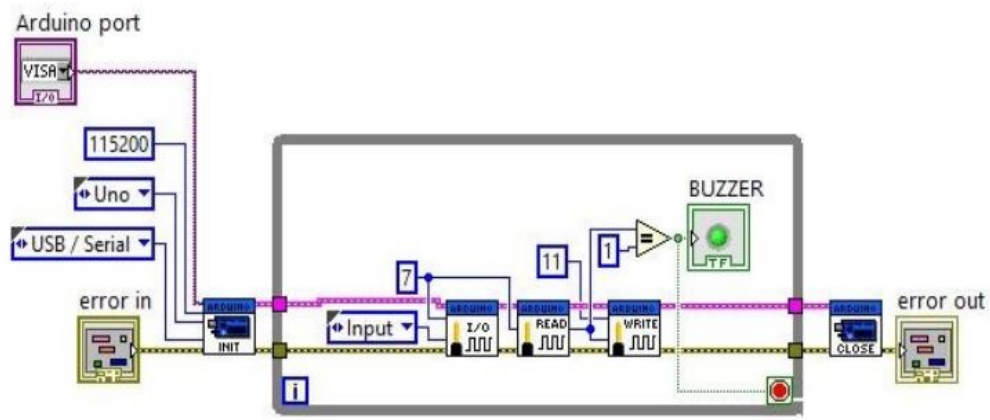

Figure 4. Block Diagram for PIR Sensor.

Source: own elaboration.

\subsection{DETECTION}

From the above Figure 3 and Figure 4 Shows the PIR sensor values in terms of digital outputs, when the motion is detected, the digital output value is high and the digital value will be low as when the no motion was detected in front of the PIR sensor. PIR sensor gives the inference of natural values into the buzzer with the help of Arduino Uno interfacing with LabVIEW 2014. When the animal was detected, the buzzer will blow. 


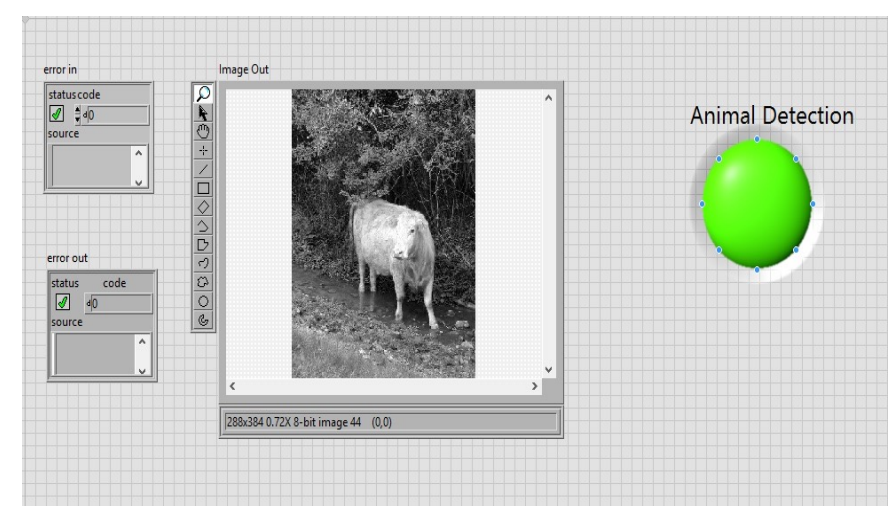

Figure 5. Front panel for animal detection.

Source: own elaboration.

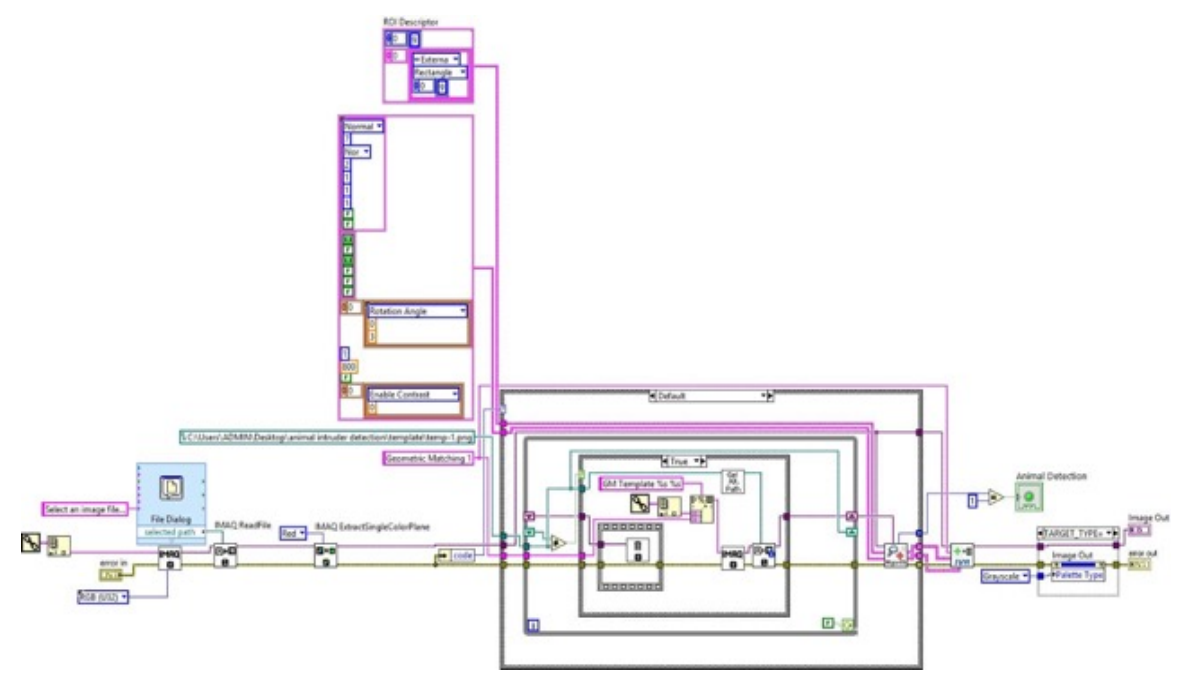

Figure 6. Block diagram for animal detection.

Source: own elaboration.

From the above Figure 5 and Figure 6 infers when the PIR sensor input is high, the corresponding camera will be going to ready for capture. Form that images is undergoing to the above image processing techniques mentioned in the section of methodology was further classified into which animal is going to intrude the field. In Figure 5, animal detection Boolean will be high at the animal was identified. 


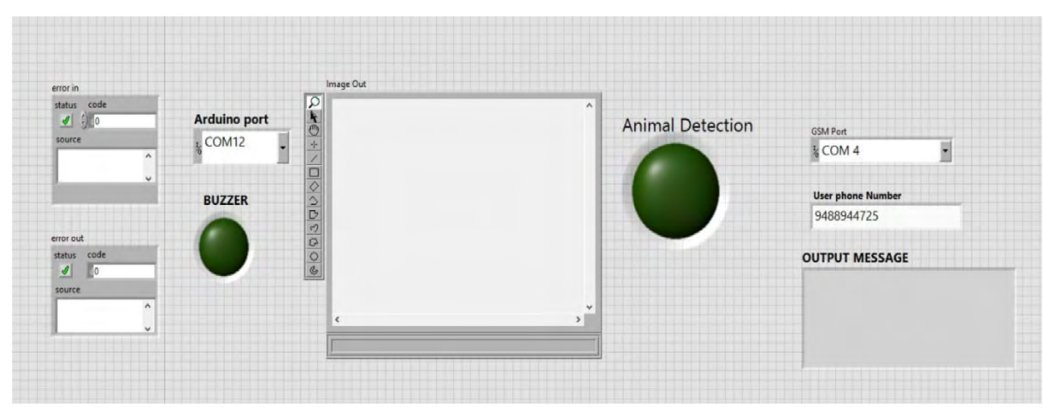

Figure 7. Front panel for animal intruder detection.

Source: own elaboration.

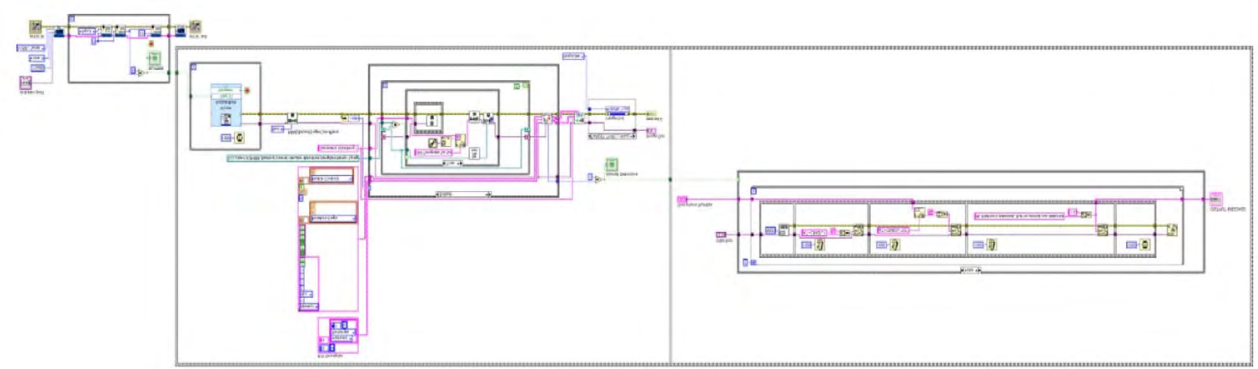

Figure 8. Block Diagram for animal intruder detection.

Source: own elaboration.

The total security creature gatecrasher identification is appeared in Figure 7 and Figure 8. At the point when the signal was blow, promptly it distinguishes which creature will barge in the field utilizing high undaunted advanced camera. After the creature location it empowers the GSM module and it will send the message of which creature would barge in the field to the clients that referenced in the client telephone number.

\section{CONCLUSIONS}

The proposed framework was recognized whether any little movement was identified in increasingly effective way. The effect of PIR sensor was increasingly exact identification of creature or individuals and with the assistance of above classifier methods distinguishes the creature with the assistance of proficient creature highlights. GSM module and Arduino unit send message after the flag recognition from the sensor and picture preparing unit. It more helps the ranchers are effectively know which creature will interrupt into the field and 
effectively screen the field if the farmers are available or not. The framework is utilized to alarm the creature independently without the farmers.

\section{REFERENCES}

Forno, F., Malnati, G., \& Portelli, G. (2005). Design and implementation of a Bluetooth ad hoc network for indoor positioning. IEE Proceedings - Software, 152(5), 223-228. https://digital-library.theiet.org/content/journals/10.1049/ip-sen_20045027

Jennings, N. R., Sycara, K., \& Wooldridge, M. A. (1998). A Roadmap of Agent Research and Development. Autonomous Agents and Multi-Agent Systems, 1(1), 7-38. https://link.springer.com/article/10.1023/A:1010090405266

Prigge, E. A., \& How, J. P. (2004). Signal architecture for a distributed magnetic local positioning system. IEEE Sensors fournal, 4(6), 864-873. https://ieeexplore.ieee.org/ document/1359849

Vossiek, M., Wiebking, L., Gulden, P., Wieghardt, J., Hoffmann, C., \& Heide, P. (2003). Wireless local positioning. IEEE Microwave Magazine, 4(4), 77-86. https:// ieeexplore.ieee.org/document/1266069

Zahrani, M. S., Ragab, K., \& U1 Haque, A. (2011). Design of GPS based system to avoid camel vehicle collisions: A Review. Asian fournal of Applied Sciences, 4(4), 362377. https://scialert.net/abstract/?doi=ajaps.2011.362.377 
